\title{
Research on College Students' Entrepreneurship based on Marketing Perspective
}

\author{
Hongyun Du \\ Shandong Xiehe University, Jinan, Shandong, 250109
}

Keywords: Marketing Strategy, College Student, Entrepreneurship.

\begin{abstract}
With the continuous transformation of the world economic situation, in the international financial crisis continues to expand and the increasing number of college graduates in China's reality, the employment of our college students face a series of severe pressure. In the face of this situation, our government actively through a variety of channels to solve this problem, and encourage and promote college students is a very important part of entrepreneurship. From a long-term perspective, college students are not only able to solve the entrepreneur's individual employment problems, but also to increase new jobs to solve more people's employment problems. And as a senior knowledge and technology students to participate in entrepreneurship, will undoubtedly China's economic restructuring and social development play a very important role. This is the value and significance of college students' entrepreneurship.
\end{abstract}

\section{Introduction}

Since the outbreak of the financial crisis triggered by subprime loans in the United States since 2008, the global economic slowdown has slowed down, and its impact on China's export-oriented economic system has spread to all aspects of social life, its huge The influence of many people unexpected. On the other hand, since the end of last century, China in order to enhance the quality of education and cultural level, began a large-scale college enrollment. This move has also raised the overall education level of the national, but also makes the employment situation becomes more and more serious. As we all know, in recent years, college graduates "graduation that is unemployed" phenomenon is common, and the impact of the export manufacturing industry and its related industries, such as foreign trade and so on has been difficult for graduates to provide appropriate jobs, so the Ministry of Education has Not to worry that the employment of Chinese college graduates is entering the reform and opening up three decades since the most difficult period. According to the Chinese Academy of Social Sciences released in 2009 statistics show that in 2009 China's college graduates for 6 million people, after the cumulative number of unemployed reached 100 million people, this pressure is unprecedented. By 2013, the number of college graduates jumped to 7.3 million. If calculated in accordance with this ratio, then the next few years, China's annual need to find the number of university graduates may be more than 10 million people. Such a large number of college students in any country in the world do not have, and this will certainly mean that the future of college students will be more serious employment. The severe employment problem makes people have to think about where the college students' career planning is. However, from another point of view, the emergence of this phenomenon is not just because of the increase in the number of employment, which is related to China's industrial transformation and the lack of small micro-enterprises are closely related. Experts pointed out that small micro-enterprise should become the main body of the future digestion and employment groups, and now the most innovative and dynamic developed countries is also emerging small micro-company. There is no doubt that the main body of small micro-enterprises are entrepreneurial enterprises, and master the high level of skills and a large number of rich knowledge of the students should become the main business company. In fact, at present our government also believes that the best way to alleviate the current employment pressure of college graduates is to "promote employment through entrepreneurship." In the context of China's growing economy, it is necessary to encourage college 
students to start their own business and adapt them to the trend of economic development and enhance their influence in the market. College students are not only able to solve their own employment problems, but also to provide employment opportunities and jobs. The most critical is that college students with their own knowledge and technology to start will undoubtedly enhance the overall technical content of our enterprises and management level, as soon as possible to promote the transformation of China's economic structure and enhance China's competitiveness in the international economic system.

\section{Analysis of the Value of Marketing}

The core of marketing is to analyze the customer's value needs. The systematic analysis of the value of the customer in the analysis and evaluation of the customer value is helpful to the design and dissemination of the public policy. The positioning of the public problem on the basis of the analysis of the customer's demand needs directly affects the development of public policy and the effect of the implementation. Therefore, from the marketing management point of view, the first thing to do is to understand the needs and desires of customers and they have to face the market, customer research, analysis of customer data, efforts to close to customers. In full understanding of customers and market conditions, marketing managers can design a customer-oriented marketing strategy, and through the creation, delivery of customer value to attract, maintain and develop the target customers. Therefore, we must solve the two questions: First, what services customers have demand, the second is how to better serve these customers. Clearly on the need to serve the needs of customers and how to create value for these customers, managers will create marketing projects to accurately deliver value to target customers. For example, the US Federal Trade Commission in the field of consumer protection, through normative research and empirical analysis to understand the interests of the public needs, accurate positioning issues proposed after a number of options for the public to comment on it, and finally held a hearing issued a public policy The It can be seen that the US Federal Trade Commission in the formulation and promotion of public policy in the process, always analyze the characteristics of public interest needs in the first place, so that the public participation in public policy development, the real value of the customer-oriented public policy service concept The

\section{Analysis on the Demand Factors of College Students' Entrepreneurship}

According to the main demand factors that affect college students' entrepreneurship, it can be found that for college students who have just entered the society, the lack of entrepreneurial funds is the main obstacle to entrepreneurship and the most eager to get support in the early days of entrepreneurship. As the social relations of college students is relatively simple, self-financing to become their main financing channels, most of the original venture from the family or friends and family, the government funding is only $1 \%$. Moreover, this financing for the long profit cycle, the high failure rate of the project a great risk, virtually to the entrepreneurial college students to bring great pressure. Second, the positive government policy for the growth of new business support directly affects the entrepreneurial wishes of college students. Although the national and provincial and municipal governments have introduced some preferential policies for college students' entrepreneurship, the policies of the different departments are not coordinated and the policies introduced are not systematic and coordinated because of the lack of communication between the functional departments in formulating policies. In addition, some entrepreneurial policies to raise the threshold to support policy applications, so many entrepreneurs are difficult to enjoy the benefits of policy, leading to the introduction of the policy cannot be a good landing, did not play its due role. Such as the provisions of the policy set by the venture capital to guide the fund, science and technology business seed funding and so on because there are many restrictions on the application, making the entrepreneur can only "Wang Mei thirst." Thirdly, entrepreneurship education can not only mobilize the enthusiasm of college students' entrepreneurship, change the employment view of college students, understand the entrepreneurial course, master the 
entrepreneurial skills and enhance the confidence of college students. The survey found that college students are more willing to accept targeted education. Because it is their urgent need to accumulate the necessary entrepreneurial experience, enhance the sense of entrepreneurship, entrepreneurial spirit and entrepreneurial ability while mastering the professional knowledge. At present, many colleges and universities only opened the elective college students entrepreneurship education class, and did not integrate into the school's overall teaching system, and the discipline of professional education did not form an organic link. And the social aspects of college students for the entrepreneurial education system are not sound enough, the lack of specialized education for college students to provide services to the training institutions. Finally, the professional accounting, advertising, consulting planning, legal, information and other services to improve the business of students also have a positive impact. The initial start-up college students due to lack of business experience, the establishment of the process of business procedures and the initial stage of operation of the organization, system development, tax returns and other management activities need specialized services to help. At present, the number of specialized organizations serving the start-up enterprises is small, the government's administrative examination and approval, information disclosure, business consulting and other aspects of the low level of professional services, a single service, business consulting, entrepreneurship training, venture financing, risk assessment Did not play enough role, but also increased the operating costs of start-ups.

\section{Students to Enhance the Business Strategy}

The prerequisite for the government to provide support for college students' entrepreneurship is that the government should fully understand the value and significance of college students' entrepreneurship, taking into account the possible contribution of college students' entrepreneurship to society. As emphasized above, the government's knowledge of college students' entrepreneurship should be carried out from various aspects such as financial support, tax relief, standardize market order and strengthen intellectual property protection. First of all, from the perspective of entrepreneurial service system, the government should work with universities. Because a considerable part of the students actually have from the school stage has been the idea of entrepreneurship, and hope that it can be put into practice. But they are not familiar with the social environment and related policies hinder this point. In addition, college students in the university business is also facing the graduation after entering the community, and if this cannot be completed between the gentle transition, then no doubt will have a bad impact on the enterprise. Therefore, the government should work with universities to provide employment policy advice, business incubation and follow-up guidance and other one-stop service, to lift the students in business may encounter some problems.

Any entrepreneur must eventually enter the community, accept the social test. In this case, the social culture will have a crucial impact on the entrepreneurship of college students. On the one hand, social culture can affect the will and decision of college students, some will not firm entrepreneur is easy because of the suspicion of people around to give up; the other hand, social culture can also affect the customer's attitude and impact on entrepreneurs, such as support Students who start a business life may express their support for college students' entrepreneurship by purchasing their company's products, and the opponents will express their opposition by refusing to buy them. When the company's products cannot be sold, is the natural thing. Therefore, in solving the problem of college students entrepreneurship, social culture is a factor to consider. In general, we need to work together, and through the concerted efforts of all parties to achieve a correct and positive public opinion.

Entrepreneurship education for the importance of entrepreneurship in this has been no secret. Colleges and universities as an important place for college students to develop their knowledge and ability, the success of their education directly determines the future development of college students. Therefore, we should pay attention to the college entrepreneurship education. Of course, the above analysis, we also know that college entrepreneurship education not only to attach importance to the entrepreneurial spirit and ability to develop, but also need to establish a complete teaching system, a 
good teacher system and a full operating environment.

\section{Conclusion}

In the future, college students will become the mainstream of entrepreneurship, they are the national development and social and economic development potential impetus. Based on this reality, our government, universities, and societies should join hands to support college students' entrepreneurship. From the government level, both need to improve their own service system, but also need to work together with the University to complete the entrepreneurial support from the university to the community a smooth transition. For colleges and universities, you need to see the value of entrepreneurship education in quality education, to achieve the combination of production and research, to attract all kinds of enterprises and entrepreneurs, social organizations and other resources; in education, application-oriented Practice as a way. Professional education should be adapted to the needs of the community, set up interdisciplinary professional; focus on general education, emphasis on humanities education, science education and professional education combined; university curriculum flexible set, pay attention to interdisciplinary, discipline penetration, take the initiative to adapt to modern science and technology and social development Need; also should pay attention to cooperation with the enterprise production and research. From the social level, mainly to establish a good and relaxed public opinion environment, to encourage college students to start, so that students do not need to face too much social and cultural pressure. In addition, entrepreneurs need to improve their quality through a variety of ways. Only such a multi-pronged approach, college students can be healthy to carry out business.

\section{References}

[1] Peng Zhengxia, Lu Genshu, Kang Hui. Effects of Individual and Social Environmental Factors on College Students' Entrepreneurship Intention [J]. Higher Engineering Education Research, 2012 (04)

[2] Zhou Guangya. The influence of active personality and professional values on college students' entrepreneurial intention [J]. Journal of Shijiazhuang University, 2012 (03)

[3] Le Guoan, Zhang Yi, Chen Hao. Contemporary college students' entrepreneurial intention influencing factors [J]. Psychology exploration, 2012 (02)

[4] Wang Jiao. Entrepreneurial intention and its relationship with entrepreneurial knowledge [J]. Science and Technology Information, 2012 (03)

[5] Ran Xiaoli. Study on the Influence of Entrepreneurship Attitude on Entrepreneurial Intention [J]. Journal of Anyang Institute of Technology, 2012 (01) 